\title{
Temperature-Dependent Dielectric Properties of Selected Subtropical and Tropical Fruits AND Associated Insect Pests
}

\author{
S. Wang, M. Monzon, Y. Gazit, J. Tang, E. J. Mitcham, J. W. Armstrong
}

\begin{abstract}
Knowledge of the dielectric properties of commodities and insect pests is important in developing thermal treatments for postharvest insect control based on radio frequency $(R F)$ and microwave energy. The dielectric properties of six subtropical and tropical fruits along with four associated insect pests were measured between 1 and $1800 \mathrm{MHz}$ using an open-ended coaxial-line probe technique and at temperatures between $20^{\circ} \mathrm{C}$ and $60^{\circ} \mathrm{C}$. The dielectric loss factor of the fruits and the insects decreased with increasing frequency at constant temperatures. Especially over 10 to $300 \mathrm{MHz}$, the log of the dielectric loss factor decreased linearly with the log of increasing frequency. The loss factor of the fruits and the insects increased almost linearly with increasing temperature at $27.12 \mathrm{MHz}$ radio frequency, but remained in a small range at $915 \mathrm{MHz}$ microwave frequency. Both the dielectric constant and the loss factor were the highest in avocado fruit. The dielectric loss factors of insects were generally larger than that of the host fruit at all tested frequencies. But those values were within the same order of magnitude, suggesting that differential heating of insects in fresh fruits was unlikely to occur in RF and microwave systems. Direct measurement of electrical conductivity of fruit pulps can also provide a good estimation of the dielectric loss factor at $27.12 \mathrm{MHz}$. Matching the electrical conductivity of saline solution can be an effective and simple means to improve heating uniformity of the fruit when subjected to RF systems.
\end{abstract}

Keywords. Electrical conductivity, Fruit fly, Microwave, Radio frequency, Temperature effect.

B oth hot water and hot air systems have been used to control fruit fly pests in a number of subtropical and tropical fruits. Because of the heat-sensitive nature of fresh fruits, a small deviation from the required parameters would result in either product damage or insect survival (Armstrong, 1994). It is important to develop effective means to uniformly deliver thermal energy to every part of the fruit where insect pests may reside to shorten treatment time and minimize thermal impacts on fruit quality. Pilot-scale radio frequency (RF) systems have been used in research on postharvest insect control in fruits and nuts (Wang et al., 2001; Birla et al., 2004; Mitcham et al., 2004). RF heating has the advantage of fast core heating of fruits because of direct interaction between the RF energy and the fruit tissue to quickly raise the center temperature, especially

Article was submitted for review in March 2005; approved for publication by the Food \& Process Engineering Institute Division of ASABE in July 2005. Presented at the 2004 ASAE Annual Meeting as Paper No. 046192.

The authors are Shaojin Wang, ASABE Member Engineer, Research Assistant Professor, and Juming Tang, ASABE Member Engineer, Professor, Department of Biological Systems Engineering, Washington State University, Pullman, Washington; Maria Monzon, Graduate Student, and Elizabeth J. Mitcham, Professor, Department of Plant Sciences, University of California, Davis, California; Yoav Gazit, Entomologist, The Israel Cohen Institute for Biological Control, Plant Production and Marketing Board-Citrus Division, Bet-Dagan, Israel; and John W. Armstrong, Supervisory Research Entomologist, USDA-ARS Pacific Basin Agricultural Research Center, Hilo, Hawaii. Corresponding author: Juming Tang, Department of Biological Systems Engineering, Washington State University, 213 L. J. Smith Hall, Pullman, WA 99164-6120; phone: 509-335-2140; fax: 509-335-2722; e-mail: jtang@ mail.wsu.edu. for large fruits. RF and microwave treatments have been suggested for control of postharvest insects (Andreuccetti et al., 1994; Hallman and Sharp, 1994; Nelson, 1996; Ikediala et al., 1999; Tang et al., 2000; Wang et al., 2002). Information on the dielectric properties of subtropical and tropical fruits associated with insect pests is essential in developing successful postharvest thermal treatments based on RF and microwave energy.

The dielectric properties of fruits provide general guidance for selecting optimum frequencies, determining appropriate electric field intensities to achieve desired heating rates, and determining the optimum thickness of the treated bed to ensure uniform RF and microwave treatments. When fresh fruits are heated by RF energy in air, fruits may suffer thermal damage (burn) at the points of contact with the container or with other fruit because the contact points form the route of least resistance for RF energy to pass (Ikediala et al., 2002; Birla et al., 2004). A water immersion technique was used to avoid non-uniform RF heating in fresh fruits (Ikediala et al., 2002; Birla et al., 2004). In those studies, RF heating uniformity was greatly improved when fruits were immersed in water in a fruit mover between the two plate electrodes with proper rotation and selection of saline solution. Knowledge of the dielectric properties of fruits can be used to select the appropriate salinity for a saline water solution to overcome overheating at the contact points and to reduce potential temperature differences between the core and the surface. In addition, by exploring the differences in the dielectric properties of the targeted insect larvae and fruits, we can predict potential differential heating in the electromagnetic field (Wang et al., 2003a).

The dielectric properties of materials are affected by many factors, including frequency, temperature, and moisture 
content. The frequency-dependent trend of the dielectric properties can provide important information about the material characteristics. In theory, electric conduction and various polarization mechanisms (including dipole, electronic, ionic, and Maxwell-Wagner) contribute to the dielectric loss factor (Tang et al., 2002). For moist dielectric materials, ionic conductivity plays a major role at lower frequencies (e.g., <200 $\mathrm{MHz}$ ), whereas both ionic conductivity and dipole rotation of free water play a combined role at microwave frequencies. The temperature of a material has a significant effect on the dielectric properties. Generally, the loss factor increases with increasing temperature at low frequencies due to ionic conductance (Guan et al., 2004) and decreases with increasing temperature at high frequencies due to free water dispersion (Wang et al., 2003b).

Many studies on the dielectric properties of agricultural and biological materials have been reported for different frequency ranges, temperatures, and moisture contents (Kent, 1987; Foster and Schwan, 1989; Ryynänen, 1995; Nelson, 1996; Venkatesh and Raghavan, 2004). The dielectric properties at temperatures of $5^{\circ} \mathrm{C}$ to $95^{\circ} \mathrm{C}$ were also reported for nine fruits and vegetables, including avocado, from 0.01 to $1.8 \mathrm{GHz}$ (Nelson, 2003). Limited reports are available on the dielectric properties of insects such as grain weevils (Nelson and Payne, 1982), potato beetles (Colpitts et al., 1992), woodworms (Andreuccetti et al., 1994), and codling moths (Ikediala et al., 2000). Recently, Wang et al. (2003b) reported the dielectric properties of codling moth, Indianmeal moth, and navel orangeworm larvae between 1 and $1800 \mathrm{MHz}$ measured with the open-ended coaxial probe technique. This method allows broadband measurements while minimizing sample disturbance. The measured reflection coefficient is related to the sample permittivity (Sheen and Woodhead, 1999). The open-ended coaxial probe method is widely used to measure the dielectric properties of food and agricultural materials because it does not require a particular sample shape or special containers (Ikediala et al., 2000; Feng et al., 2002; Nelson, 2003; Wang et al., 2003b). However, no data have been reported on the dielectric properties of the subtropical and tropical fruits associated with quarantine insect pest control. Reliable dielectric property data for the targeted insects and fruits over a range of temperatures between $20^{\circ} \mathrm{C}$ and $60^{\circ} \mathrm{C}$ will be crucial in designing and modeling practical pest control treatment processes based on electromagnetic energy.

The objectives of this research were: (1) to study dielectric characteristics of four important insect pests (Mediterranean fruit fly, Mexican fruit fly, oriental fruit fly, and melon fly) and six subtropical and tropical fruits (avocado, cherimoya, longan, passion fruit, persimmon, and white sapote); (2) to determine effects of frequency (1 to $1800 \mathrm{MHz}$ ) and temperature $\left(20^{\circ} \mathrm{C}\right.$ to $\left.60^{\circ} \mathrm{C}\right)$ on dielectric properties; (3) to determine the penetration depth of those fruits at frequencies $(27.12,915$, and $1800 \mathrm{MHz})$ commonly used in dielectric heating applications; and (4) to explore the salinity of saline solutions that matches the dielectric loss factor of fruits to provide uniform heating when subjected to RF energy.

\section{Materials and Methods DiELECTRIC THEORY}

Permittivity is a quantity used to describe the dielectric properties that influence reflection of electromagnetic waves at interfaces and the attenuation of the wave energy within materials. The complex relative permittivity $\left(\varepsilon^{*}\right)$ of a material to that of free space can be expressed in the following form:

$$
\varepsilon^{*}=\varepsilon^{\prime}-j \varepsilon^{\prime \prime}
$$

The real part $\left(\varepsilon^{\prime}\right)$ is referred to as the dielectric constant and reflects the ability of the material to store energy when the material is exposed to an electric field, while the dielectric loss factor $\left(\varepsilon^{\prime \prime}\right)$, which is the imaginary part, influences energy absorption and attenuation, and $j=\sqrt{-1}$. Mechanisms that contribute to the dielectric loss in heterogeneous mixtures include polar, electronic, atomic, and Maxwell-Wagner responses (Metaxas and Meredith, 1993). At $\mathrm{RF}$ and microwave frequencies of practical importance and currently used for applications in material processing (RF of 1 to $50 \mathrm{MHz}$ and microwave frequencies of 915 and $2450 \mathrm{MHz}$ ), ionic conduction and dipole rotation are the dominant loss mechanisms (Ryynänen, 1995):

$$
\varepsilon^{\prime \prime}=\varepsilon_{d}^{\prime \prime}+\varepsilon_{\sigma}^{\prime \prime}
$$

with

$$
\varepsilon_{\sigma}^{\prime \prime}=\frac{\sigma}{2 \pi f \varepsilon_{0}}
$$

where subscripts $d$ and $\sigma$ stand for contributions due to dipole rotation and ionic conduction, respectively; $\sigma$ is the ionic conductivity $\left(\mathrm{S} \mathrm{m}^{-1}\right)$ of a material, $f$ is the frequency $(\mathrm{Hz})$, and $\varepsilon_{0}$ is the permittivity of free space or vacuum $(8.854 \times$ $\left.10^{-12} \mathrm{~F} \mathrm{~m}^{-1}\right)$. Dielectric lossy materials convert electric energy at RF and microwave frequencies into heat. The increase in temperature $(\Delta T)$ of a material at any location in a fruit can be calculated when the heat conduction in the material and heat loss to the surroundings are negligible (Wang et al., 2003a):

$$
\rho C_{p} \frac{\Delta T}{\Delta t}=5.563 \times 10^{-11} f E^{2} \varepsilon^{\prime \prime}
$$

where $C_{p}$ is the specific heat of the material $\left(\mathrm{J} \mathrm{kg}^{-1}{ }^{\circ} \mathrm{C}^{-1}\right), \rho$ is the density of the material $\left(\mathrm{kg} \mathrm{m}^{-3}\right), E$ is the electric field intensity $\left(\mathrm{V} \mathrm{m}^{-1}\right), \Delta t$ is the time duration (s), and $\Delta T$ is the temperature rise in the material $\left({ }^{\circ} \mathrm{C}\right)$. It is clear from equation 4 that the rise in temperature is proportional to the material's dielectric loss factor, in addition to electric field intensity squared, frequency, and treatment time.

In dielectric materials, the electric field strength decreases with distance $(z)$ from the surface and is written as:

$$
E=E_{o} e^{-\alpha z}
$$

where $E_{o}$ is the electric field strength just below the surface of a dielectric material. The attenuation factor $(\alpha)$ depends on the dielectric properties of the material (von Hippel, 1954) and is given by:

$$
\alpha=\frac{2 \pi f}{c}\left[\frac{1}{2} \varepsilon^{\prime}\left(\sqrt{1+\left(\frac{\varepsilon^{\prime \prime}}{\varepsilon^{\prime}}\right)^{2}}-1\right)\right]^{\frac{1}{2}}
$$

where $c$ is the speed of light in free space $\left(3 \times 10^{8} \mathrm{~m} \mathrm{~s}^{-1}\right)$. Substituting equation 5 by power, one obtains:

$$
P=P_{o} e^{-2 \alpha z}
$$


where $P_{o}$ is the power just below the surface of a dielectric material.

Penetration depth of microwave and RF power is defined as the depth where the power is reduced to 1/e $(e=2.718)$ of the power entering the surface. The penetration depth $\left(d_{p}\right.$, in $\mathrm{m}$ ) of RF and microwave energy in a lossy material can be calculated by (von Hippel, 1954):

$$
d_{p}=\frac{c}{2 \pi f \sqrt{2 \varepsilon^{\prime}\left[\sqrt{1+\left(\frac{\varepsilon^{\prime \prime}}{\varepsilon^{\prime}}\right)^{2}}-1\right]}}
$$

After obtaining the dielectric properties, the penetration depths of electromagnetic energy in selected materials can be calculated. Given fixed dielectric properties, the penetration depth of a material is inversely proportional to frequency. It is, therefore, expected that, in general, deeper penetration corresponds to lower frequencies, and that higher frequencies result in greater surface heating. It should be noted that the dielectric properties of lossy materials vary with frequency, but penetration depth does not vary exactly as $1 / f$. Nevertheless, electromagnetic waves with short wave length do not penetrate deeply into most moist media, where the dielectric constants and the loss factors are relatively high.

\section{Sample Preparation}

Six samples of fresh subtropical and tropical fruits were obtained from local orchards in California and shipped to Washington State University (WSU), Pullman, Washington, by Federal Express to reduce quality losses. The fruit samples included green skin 'Gwen' avocado (Persea americana), 'Lisa' cherimoya (Annona cherimola), longan (Euphoria longana), purple skin passion fruit (Passiflora edulis), 'Fuyu' persimmon (Diospyros kaki), and 'Vernon' white sapote (Casimiroa edulis). The initial moisture contents, tissue density, and total soluble solids of these fresh fruits were $75 \%$ to $87 \%$ w.b. (wet basis), 0.8 to $1.1 \mathrm{~g} \mathrm{~cm}^{-3}$, and $15 \%$ to $25 \%$, respectively (Holland et al., 1992; Nelson, 2003). Mature fruit flesh (pulp) was used for the dielectric property measurements. An electric blender was used to break the fruit flesh into paste. The electrical conductivity measurements were conducted at $20^{\circ} \mathrm{C}$ using a benchtop conductivity meter (CON 500 meter w/probe, Oakton Instruments, Vernon Hills, Ill.) with three replicates.

Third-instar Mexican fruit flies (Anastrepha ludens L.), were reared at the USDA-ARS Crop Quality and Research Laboratory, Weslaco, Texas. All live larvae were immersed in tap water in sealed glass bottles. They were packed in insulated shipping cartons and shipped via overnight delivery to WSU quarantine facilities. The larvae were separated from water at WSU. The surface water was removed by a paper towel and then blended. Two developmental stages of the Mediterranean fruit fly (Ceratitis capitata) (Medfly), fresh oviposited eggs and pre-pupae (mature third-instars), were obtained from the Israel Cohen Institute for Biological Control, Bet-Dagan, Israel. The eggs and larvae were collected every hour from clean trays that were placed under the fly cages and frozen in dry ice. The pre-pupae were collected at the "popping stage," when exiting their diet to pupate. The third-instar larvae of melon fly (Bactrocera cucurbitae) and oriental fruit fly (Bactrocera dorsalis) were obtained from the USDA-ARS Pacific Basin Agricultural
Research Center, Hilo, Hawaii. Insects were kept frozen during the shipment to WSU and in storage until the preparation of the slurry for dielectric property analysis. Based on our previous study (Ikediala et al., 2000), both the dielectric constant and the loss factor of blended codling moth larvae had no significant differences from that of live larvae at room temperature. Before starting dielectric property measurements, the insect eggs and larvae in the bottles were thawed using warm distilled water within 2 min and dried with paper towel and blended into a slurry. The initial moisture content of fruit fly larvae slurry was $72 \%$ to $78 \%$ on a wet basis (w.b.). About $30 \mathrm{~cm}^{3}$ of slurry was used for each sample to avoid electromagnetic field perturbation by the sample holder. Tests with insect larvae were conducted immediately after blending to minimize degradation of the hemolymph and other constituents.

\section{Dielectric Property Measurement System}

Dielectric properties of samples were measured between $1 \mathrm{MHz}$ and $1800 \mathrm{MHz}$ using the open-ended coaxial probe technique with an Impedance Analyzer (model 4291B, Innovative Measurement Solutions, Inc., Santa Clara, Cal.). This frequency range covers three U.S. Federal Communications Commission (FCC) allocated RF frequencies $(13,27$, and $40 \mathrm{MHz}$ ) and one microwave frequency $(915 \mathrm{MHz})$ for industrial heating applications. The upper frequency $(1800 \mathrm{MHz})$ is close to another FCC allocated microwave frequency $(2,450 \mathrm{MHz})$. Because thermal treatments for controlling insects in commodities are generally conducted at temperatures between $20^{\circ} \mathrm{C}$ and $60^{\circ} \mathrm{C}$, this temperature range was used for measuring the dielectric properties. A detailed description of the system can be found in Wang et al. (2003a, 2003c). The sample was confined in a stainless steel cell to allow the coaxial probe to fit into the cell and to be in close contact with the sample (fig. 1). The sample temperature was controlled by circulating water $\left(15 \mathrm{~L} \mathrm{~min}^{-1}\right)$ from a water bath (model 1157, VWR Scientific Products, Niles, Ill.) into the jacket of the test cell. A 50\% water and 50\% ethylene glycol solution was used as a heat transfer medium. A type- $\mathrm{T}$ thermocouple $(0.8 \mathrm{~mm}$ diameter and $0.8 \mathrm{~s}$ response time) was used to monitor the sample temperature.

\section{Measurement Procedure}

Before the dielectric properties were measured, the Impedance Analyzerr (Hewlett Packard, Santa Clara, Cal.) was warmed up for at least $1 \mathrm{~h}$ and then calibrated with air,

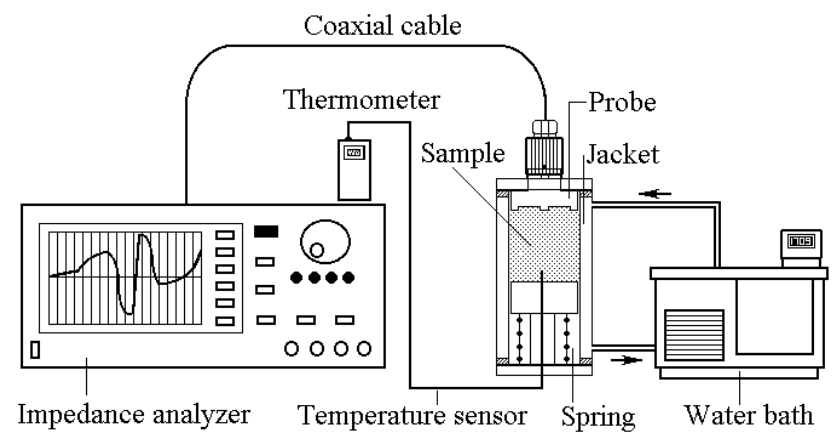

Figure 1. Schematic diagram of the dielectric properties measurement system (not to scale). 
a short, a $50 \Omega$ load, and a low-loss capacitor. The Impedance Analyzer and the coaxial probe were further calibrated with a standard air-short-triple deionized water calibration procedure. Typical error of the system was about 5\% after following the standard calibration process. After calibration, the dielectric properties of insect slurry and selected commodities were measured by the Impedance Analyzer while the cable was fixed in the same shape and position to avoid any disturbances during the tests. Before and after each measurement, the probe and the sample cell were cleaned with deionized water and wiped dry. The dielectric properties of each sample were measured at 200 discrete frequencies between 1 and $1800 \mathrm{MHz}$ at $20^{\circ} \mathrm{C}, 30^{\circ} \mathrm{C}, 40^{\circ} \mathrm{C}, 50^{\circ} \mathrm{C}$, and $60^{\circ} \mathrm{C}$. Each frequency sweep took about $2 \mathrm{~min}$. After each measurement, the water bath was adjusted to the next temperature level, with sample temperatures reaching the desired level in about $10 \mathrm{~min}$. The dielectric property data for insects and fruits were determined in duplicate. Mean values and standard deviations were calculated from two replicates.

\section{Correlation Between Electrical Conductivity and LOSS FACTOR}

To evaluate the influence of electrical conductivity of fruit pulp on its dielectric loss factor, the following equation was obtained by taking a logarithm on both sides of equation 3 :

$$
\log \varepsilon_{\sigma}^{\prime \prime}=-\log f+\log \frac{\sigma}{2 \pi \varepsilon_{0}}
$$

Equation 9 shows a linear relationship between the dielectric loss factor contributed by ionic conductance and the frequency in a log-log plot. The measured and calculated dielectric loss factors of the fruits were plotted and compared against the frequency. From this plot, the estimated precision of the dielectric loss factor might be determined based on the electrical conductivity measurements as a function of frequency.

When the dipole term at the right side of equation 2 was neglected at $27.12 \mathrm{MHz}$, the electrical conductivity can be estimated from the measured dielectric loss factor by the following equation:

$$
\sigma=2 \pi f \varepsilon_{0} \varepsilon^{\prime}
$$

The electrical conductivity estimated from lost factor using equation 10 was compared with the value measured directly by the electrical conductivity meter. If the difference was small between the two methods, a simple measurement of the electrical conductivity of the fruit can be used as a means to estimate the dielectric loss factor, or vice versa. Using the previous data on saline $(\mathrm{NaCl})$ solutions (Ikediala et al., 2002), a linear relationship was developed in this study between the concentration (\%) and the electrical conductivity $\left(\mathrm{mS} \mathrm{cm}^{-1}\right)$. This relationship was further used to estimate the saline concentration using the measured electrical conductivity of the fruit. This information is useful in matching the dielectric properties of saline solution to that of the fruit to ensure uniform heating in an RF system.

\section{Results AND Discussions}

\section{Frequency-Dependent Dielectric Properties}

Because of the congested bands of RF and microwaves already being used for communication purposes, the FCC al- located five frequencies for industrial, scientific, and medical applications: $13.56,27.12$, and $40.68 \mathrm{MHz}$ in the RF range and 915 and $2,450 \mathrm{MHz}$ in the microwave range. In this study, we will focus the discussion on 27.12 and $915 \mathrm{MHz}$, which are commonly used for postharvest insect control and food sterilization. Mean values for the dielectric constant and the loss factor of avocado, cherimoya, longan, passion fruit, persimmon, and white sapote at $20^{\circ} \mathrm{C}$ are shown in figure 2 . The dielectric properties of the six subtropical and tropical fruits had a similar trend and decreased with increasing frequency. Both the dielectric constant and the loss factor of avocado were the largest among the test fruits, especially at $27.12 \mathrm{MHz}$. This was caused mainly by the highest salt content of avocado pulp. These mean values for avocado were comparable to those obtained by Nelson (2003). The detailed dielectric properties of the six fruits at four frequencies and five temperatures are listed in table 1.

Values for the dielectric constant and the loss factor of four fruit fly larvae at $20^{\circ} \mathrm{C}$ are shown in figure 3 and table 2 . Both the dielectric constant and the loss factor decreased with increasing frequency. There were no clear differences in the dielectric properties among the four larvae. Melon and oriental fruit fly larvae had slightly larger loss factors than Mexican fruit fly and Medfly at 27.12 MHz. Table 1 shows that the loss factor of Medfly larvae was larger than that of Medfly eggs.

\section{Temperature-Dependent Dielectric Properties}

Figure 4 shows an example of the dielectric loss factor of avocado as influenced by temperature. The dielectric loss
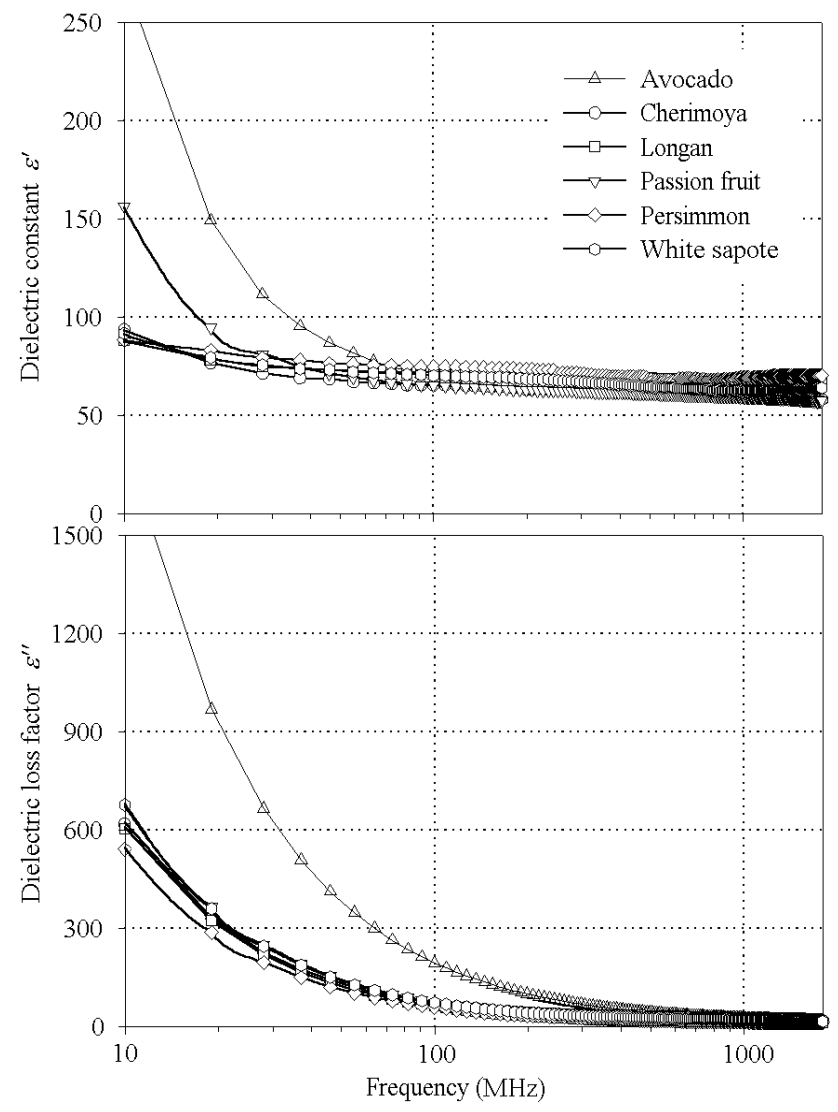

Figure 2. Dielectric constant $\left(\varepsilon^{\prime}\right)$ and loss factor $\left(\varepsilon^{\prime \prime}\right)$ of six subtropical and tropical fruits at $20^{\circ} \mathrm{C}$. 
Table 1. Dielectric properties (mean \pm SD) of six subtropical and tropical fruits at five temperatures and four frequencies.

\begin{tabular}{|c|c|c|c|c|c|c|c|c|c|}
\hline \multirow[b]{2}{*}{ Material } & \multirow{2}{*}{$\begin{array}{c}\text { Temp. } \\
\left({ }^{\circ} \mathrm{C}\right)\end{array}$} & \multicolumn{4}{|c|}{ Constant at Frequency $(\mathrm{MHz})$} & \multicolumn{4}{|c|}{ Loss Factor at Frequency $(\mathrm{MHz})$} \\
\hline & & 27.12 & 40 & 915 & 1800 & 27.12 & 40 & 915 & 1800 \\
\hline \multirow{5}{*}{ Avocado } & 20 & $115.7 \pm 15.8$ & $92.7 \pm 8.1$ & $59.9 \pm 0.6$ & $58.2 \pm 0.6$ & $699.6 \pm 10.3$ & $477.2 \pm 8.5$ & $27.4 \pm 0.6$ & $19.0 \pm 0.2$ \\
\hline & 30 & $123.7 \pm 20.8$ & $96.3 \pm 10.5$ & $58.9 \pm 0.7$ & $57.3 \pm 0.6$ & $814.3 \pm 12.5$ & $555.3 \pm 10.7$ & $30.5 \pm 0.7$ & $20.0 \pm 0.3$ \\
\hline & 40 & $131.6 \pm 25.1$ & $100.0 \pm 12.6$ & $57.8 \pm 0.9$ & $56.4 \pm 0.9$ & $951.6 \pm 13.4$ & $648.6 \pm 11.7$ & $34.3 \pm 0.8$ & $21.3 \pm 0.4$ \\
\hline & 50 & $137.9 \pm 29.1$ & $103.7 \pm 14.6$ & $57.9 \pm 0.3$ & $56.7 \pm 0.0$ & $1136.2 \pm 0.2$ & $774.0 \pm 3.3$ & $39.8 \pm 0.2$ & $23.8 \pm 0.1$ \\
\hline & 60 & $140.5 \pm 31.6$ & $105.4 \pm 15.5$ & $59.8 \pm 1.8$ & $58.7 \pm 1.9$ & $1422.0 \pm 87.0$ & $965.1 \pm 53.8$ & $47.8 \pm 2.1$ & $27.7 \pm 1.2$ \\
\hline \multirow{5}{*}{ Cherimoya } & 20 & $71.5 \pm 6.5$ & $68.6 \pm 6.4$ & $50.9 \pm 11.6$ & $59.0 \pm 4.6$ & $238.5 \pm 29.8$ & $163.4 \pm 19.5$ & $25.4 \pm 2.7$ & $18.3 \pm 1.4$ \\
\hline & 30 & $72.1 \pm 5.1$ & $68.9 \pm 4.7$ & $50.5 \pm 7.7$ & $58.5 \pm 3.7$ & $283.1 \pm 31.7$ & $193.0 \pm 21.3$ & $27.2 \pm 1.4$ & $17.1 \pm 0.9$ \\
\hline & 40 & $68.4 \pm 8.4$ & $64.5 \pm 8.3$ & $48.7 \pm 13.3$ & $56.9 \pm 4.1$ & $339.1 \pm 37.7$ & $231.0 \pm 24.9$ & $26.0 \pm 5.2$ & $17.0 \pm 2.5$ \\
\hline & 50 & $72.0 \pm 4.2$ & $68.0 \pm 3.8$ & $62.0 \pm 6.8$ & $57.5 \pm 2.4$ & $406.4 \pm 47.1$ & $275.4 \pm 31.8$ & $29.1 \pm 4.3$ & $17.6 \pm 2.1$ \\
\hline & 60 & $70.0 \pm 5.0$ & $65.4 \pm 4.6$ & $56.0 \pm 10.2$ & $55.7 \pm 3.5$ & $480.6 \pm 57.7$ & $325.6 \pm 38.7$ & $31.5 \pm 2.3$ & $17.8 \pm 2.3$ \\
\hline \multirow{5}{*}{ Longan } & 20 & $75.2 \pm 3.0$ & $73.8 \pm 2.6$ & $68.2 \pm 1.9$ & $66.3 \pm 1.8$ & $230.1 \pm 8.7$ & $156.5 \pm 5.9$ & $13.3 \pm 0.5$ & $14.1 \pm 0.4$ \\
\hline & 30 & $73.5 \pm 2.9$ & $71.8 \pm 2.4$ & $66.0 \pm 1.6$ & $64.6 \pm 1.6$ & $276.1 \pm 9.2$ & $187.8 \pm 6.3$ & $13.5 \pm 0.5$ & $12.8 \pm 0.4$ \\
\hline & 40 & $71.6 \pm 3.2$ & $69.5 \pm 2.6$ & $63.4 \pm 1.5$ & $62.3 \pm 1.5$ & $326.4 \pm 10.6$ & $221.9 \pm 7.4$ & $14.1 \pm 0.5$ & $12.1 \pm 0.5$ \\
\hline & 50 & $69.7 \pm 3.7$ & $67.3 \pm 2.9$ & $60.8 \pm 1.7$ & $59.9 \pm 1.7$ & $377.7 \pm 13.1$ & $256.7 \pm 9.1$ & $15.0 \pm 0.6$ & $11.7 \pm 0.4$ \\
\hline & 60 & $67.5 \pm 4.4$ & $65.0 \pm 3.1$ & $58.3 \pm 1.9$ & $57.6 \pm 1.9$ & $431.4 \pm 16.6$ & $293.3 \pm 11.4$ & $16.0 \pm 0.7$ & $11.7 \pm 0.6$ \\
\hline \multirow{5}{*}{ Passion fruit } & 20 & $82.7 \pm 0.7$ & $73.5 \pm 1.5$ & $59.7 \pm 2.6$ & $57.8 \pm 2.6$ & $264.1 \pm 8.6$ & $179.7 \pm 5.6$ & $15.0 \pm 1.3$ & $14.0 \pm 1.4$ \\
\hline & 30 & $84.9 \pm 0.5$ & $73.9 \pm 0.7$ & $58.6 \pm 2.4$ & $56.7 \pm 2.2$ & $310.7 \pm 6.0$ & $211.3 \pm 3.8$ & $14.6 \pm 0.5$ & $12.8 \pm 0.7$ \\
\hline & 40 & $88.1 \pm 2.0$ & $74.7 \pm 0.6$ & $57.2 \pm 1.7$ & $55.6 \pm 1.5$ & $373.6 \pm 1.0$ & $254.1 \pm 0.4$ & $16.2 \pm 0.1$ & $12.9 \pm 0.5$ \\
\hline & 50 & $91.6 \pm 3.1$ & $75.7 \pm 1.4$ & $55.5 \pm 1.1$ & $54.1 \pm 0.9$ & $441.2 \pm 1.3$ & $300.1 \pm 1.3$ & $17.6 \pm 0.2$ & $13.0 \pm 0.3$ \\
\hline & 60 & $96.6 \pm 4.5$ & $77.7 \pm 2.4$ & $54.2 \pm 0.9$ & $52.9 \pm 0.7$ & $523.9 \pm 4.2$ & $356.3 \pm 3.5$ & $19.6 \pm 0.2$ & $13.5 \pm 0.2$ \\
\hline \multirow{5}{*}{ Persimmon } & 20 & $79.8 \pm 0.4$ & $77.6 \pm 0.3$ & $68.4 \pm 6.7$ & $70.3 \pm 1.9$ & $207.5 \pm 14.5$ & $141.1 \pm 10.1$ & $21.1 \pm 6.0$ & $15.3 \pm 1.7$ \\
\hline & 30 & $79.1 \pm 0.1$ & $76.4 \pm 0.3$ & $73.2 \pm 1.1$ & $70.3 \pm 0.8$ & $247.9 \pm 17.4$ & $168.0 \pm 11.8$ & $16.3 \pm 0.1$ & $13.3 \pm 0.3$ \\
\hline & 40 & $77.6 \pm 0.2$ & $74.5 \pm 0.3$ & $70.8 \pm 0.8$ & $68.3 \pm 0.6$ & $295.6 \pm 20.6$ & $200.0 \pm 13.9$ & $15.9 \pm 0.0$ & $12.1 \pm 0.4$ \\
\hline & 50 & $76.6 \pm 0.2$ & $72.8 \pm 0.3$ & $68.5 \pm 0.6$ & $66.3 \pm 0.5$ & $346.4 \pm 23.7$ & $234.5 \pm 15.9$ & $16.1 \pm 0.2$ & $11.5 \pm 0.4$ \\
\hline & 60 & $75.4 \pm 0.3$ & $71.0 \pm 0.3$ & $66.0 \pm 0.5$ & $64.1 \pm 0.4$ & $401.3 \pm 28.2$ & $271.5 \pm 19.0$ & $16.9 \pm 0.0$ & $11.2 \pm 0.4$ \\
\hline \multirow{5}{*}{$\begin{array}{l}\text { White } \\
\text { sapote }\end{array}$} & 20 & $76.0 \pm 0.3$ & $73.6 \pm 0.4$ & $62.6 \pm 2.2$ & $64.0 \pm 1.5$ & $258.6 \pm 12.4$ & $176.0 \pm 8.6$ & $24.0 \pm 0.5$ & $16.8 \pm 0.2$ \\
\hline & 30 & $75.4 \pm 0.4$ & $72.6 \pm 0.5$ & $55.5 \pm 4.9$ & $62.7 \pm 0.3$ & $307.1 \pm 12.7$ & $208.8 \pm 8.5$ & $24.2 \pm 0.4$ & $16.1 \pm 0.3$ \\
\hline & 40 & $75.5 \pm 0.5$ & $72.2 \pm 0.4$ & $58.1 \pm 2.3$ & $62.0 \pm 0.5$ & $369.9 \pm 17.6$ & $251.3 \pm 12.0$ & $26.2 \pm 0.4$ & $15.7 \pm 0.4$ \\
\hline & 50 & $74.5 \pm 0.7$ & $70.6 \pm 0.6$ & $60.3 \pm 0.9$ & $60.9 \pm 0.1$ & $433.1 \pm 17.5$ & $293.9 \pm 11.8$ & $24.9 \pm 1.0$ & $15.3 \pm 0.4$ \\
\hline & 60 & $69.1 \pm 1.9$ & $64.9 \pm 1.9$ & $52.8 \pm 0.5$ & $55.5 \pm 1.9$ & $470.8 \pm 9.4$ & $319.4 \pm 6.5$ & $25.3 \pm 3.2$ & $14.5 \pm 0.8$ \\
\hline
\end{tabular}

factor increased almost linearly with increasing temperature at $27.12 \mathrm{MHz}$. The dielectric constant for avocado also increased with increasing temperature at $27.12 \mathrm{MHz}$ (table 1). At $915 \mathrm{MHz}$, the dielectric constant for avocado remained almost constant, but its loss factor increased with increasing temperature. At $27.12 \mathrm{MHz}$, avocado had the highest dielectric loss factor, followed by passion fruit, white sapote, cherimoya, longan, and persimmon having the lowest range for $\varepsilon^{\prime \prime}$. The dielectric constants of cherimoya, longan, passion fruit, persimmon, and white sapote showed no clear changes with increasing temperature both at 27.12 and $915 \mathrm{MHz}$. Loss factors of cherimoya, longan, passion fruit, persimmon, and white sapote increased significantly with increasing temperature at $27.12 \mathrm{MHz}$, but at $915 \mathrm{MHz}$ loss factors remained within a small range (such as 13.3 to 16.0 for longan and 24 to 26.2 for white sapote) at temperatures from $20^{\circ} \mathrm{C}$ to $60^{\circ} \mathrm{C}$.

The dielectric constant for the targeted insects increased with increasing temperature at $27.12 \mathrm{MHz}$ but remained almost constant at $915 \mathrm{MHz}$ (table 2). The dielectric loss factors for the insects increased with increasing temperature both at 27.12 and $915 \mathrm{MHz}$. At $27.12 \mathrm{MHz}$, oriental fruit fly larvae had the highest value of dielectric loss factor, followed by the melon fly, Medfly larvae, Mexican fruit fly, and Medfly eggs having the lowest range of $\varepsilon^{\prime \prime}$. Although the loss factor of oriental fruit fly was about two times the values of persimmon, differential heating of the insects is unlikely to occur in the host fruits because differential heating was not observed in microwave heating of infested walnuts even when the loss factor of codling moth larvae was 10 times larger than that of walnuts at $915 \mathrm{MHz}$ (Wang et al., 2003a).

\section{Penetration Depth}

Penetration depths of electromagnetic energy for the six subtropical and tropical fruits at $20^{\circ} \mathrm{C}$ were calculated from the measured dielectric properties at 27.12, 915, and $1800 \mathrm{MHz}$ (table 3). The penetration depth decreased with increasing frequency. Avocado had the smallest penetration depth among the six fruits at $27.12 \mathrm{MHz}$ and a similar magnitude of penetration depth at $1800 \mathrm{MHz}$. The penetration depths for cherimoya, longan, passion fruit, persimmon, and white sapote were similar at $27.12 \mathrm{MHz}$, and were close to that for orange and grapefruit (Wang et al., 2003b). These penetration depths at $27.12 \mathrm{MHz}$ might make it possible to design a continuous operation with conveyor belts transporting single-layer products between two RF plate electrodes. Limited penetration depths led to non-uniform heating in large fruits, especially in the microwave frequency region. A large variation of temperatures reported by Seo et al. (1970) could be interpreted by the penetration depth data when using $2450 \mathrm{MHz}$ microwaves to treat mangoes.

\section{Matching Salinity of Immersion Solution to Fruit Electrical Conductivity}

The $\log$ of the measured and calculated dielectric loss factors $\left(\varepsilon^{\prime \prime}\right)$ for avocado and passion fruit are shown in figure 5. The calculation was made using equation 9 from the 

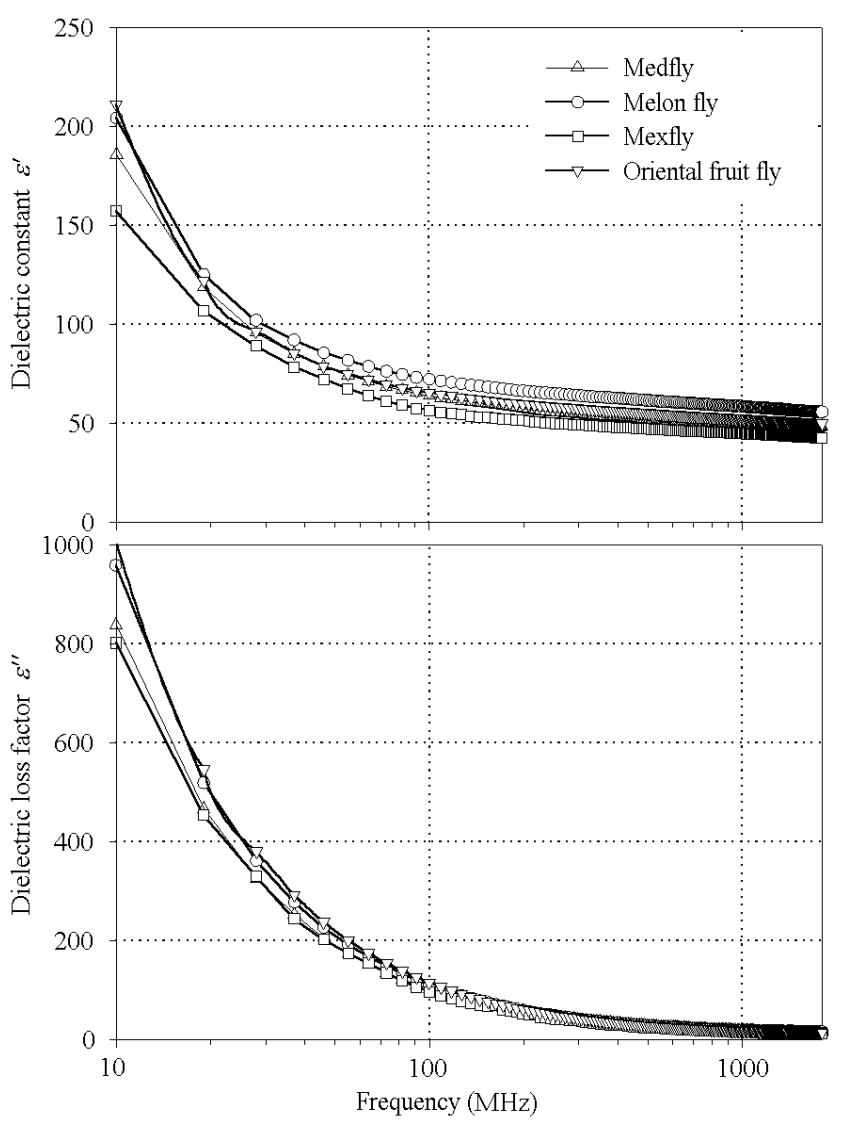

Figure 3. Dielectric constant $\left(\varepsilon^{\prime}\right.$ and loss factor $\left(\varepsilon^{\prime \prime}\right)$ of four fruit fly larvae at $20^{\circ} \mathrm{C}$. electrical conductivity at $20^{\circ} \mathrm{C}$. There was a good linear relationship between the $\log$ of $\varepsilon^{\prime \prime}$ and the $\log$ of frequency over the range from 10 to about $300 \mathrm{MHz}$. The slopes of measured dielectric loss factor versus the frequency were -0.958 and -0.938 for avocado and passion fruit, respectively, which were close to -1 for the calculated slope in equation 9 . The values of $\varepsilon^{\prime \prime}$ calculated from the direct measurement of electric conductivity slightly underestimated that measured by the open-ended coaxial probe method over the frequency range from 10 to about $300 \mathrm{MHz}$. The differences were likely the contribution of dipole water molecules $\left(\varepsilon_{d}{ }^{\prime \prime}\right)$ to the measured total dielectric loss factor $\left(\varepsilon^{\prime \prime}\right)$. The data shown in figure 5 confirmed that the dielectric loss factor due to the ionic conductivity $\left(\varepsilon_{\sigma}{ }^{\prime \prime}\right)$ of the fruits dominated the total dielectric loss factor at the mentioned low frequency range. But at frequencies higher than $300 \mathrm{MHz}$, the dipole water molecules had an increasingly important contribution to the total $\varepsilon^{\prime \prime}$ with increasing frequency (fig. 5).

Table 4 shows a comparison of the electrical conductivity of subtropical and tropical fruits estimated from the dielectric loss factor at $27.12 \mathrm{MHz}$ using equation 10 and from direct measurement with the electrical conductivity meter at $20^{\circ} \mathrm{C}$. The estimated electrical conductivity from $\varepsilon^{\prime \prime}$ was higher than the measured value for all six fruits due to the fact that the dielectric loss factor measurement might include contributions other than ionic conductivity even at low frequencies. This difference ranged from $5 \%$ to $28 \%$ depending on the fruit. Based on the established relationship between concentration and conductivity of $\mathrm{NaCl}$ solutions (fig. 6), the required $\mathrm{NaCl}$ concentration for matching the dielectric loss factor of the subtropical and tropical fruits is also given in table 4 .

In order to validate the correlation between the electrical conductivity and the dielectric loss factor established for the

Table 2. Dielectric properties (mean $\pm \mathrm{SD}$ ) of five insects at five temperatures and four frequencies.

\begin{tabular}{|c|c|c|c|c|c|c|c|c|c|}
\hline \multirow[b]{2}{*}{ Material } & \multirow{2}{*}{$\begin{array}{l}\text { Temp. } \\
\left({ }^{\circ} \mathrm{C}\right)\end{array}$} & \multicolumn{4}{|c|}{ Constant at Frequency $(\mathrm{MHz})$} & \multicolumn{4}{|c|}{ Loss Factor at Frequency $(\mathrm{MHz})$} \\
\hline & & 27.12 & 40 & 915 & 1800 & 27.12 & 40 & 915 & 1800 \\
\hline \multirow{5}{*}{$\begin{array}{l}\text { Medfly } \\
\text { egg }\end{array}$} & 20 & $107.6 \pm 0.3$ & $85.8 \pm 0.5$ & $47.4 \pm 0.4$ & $45.5 \pm 0.1$ & $235.1 \pm 1.1$ & $168.5 \pm 1.0$ & $15.6 \pm 0.9$ & $11.9 \pm 0.1$ \\
\hline & 30 & $118.9 \pm 0.2$ & $92.7 \pm 0.6$ & $47.4 \pm 0.1$ & $45.7 \pm 0.2$ & $278.5 \pm 0.3$ & $199.7 \pm 0.2$ & $16.7 \pm 0.7$ & $12.0 \pm 0.1$ \\
\hline & 40 & $131.8 \pm 1.1$ & $100.4 \pm 1.0$ & $47.1 \pm 0.3$ & $45.5 \pm 0.1$ & $334.1 \pm 3.6$ & $239.0 \pm 2.6$ & $18.1 \pm 0.3$ & $12.3 \pm 0.2$ \\
\hline & 50 & $143.7 \pm 1.3$ & $107.5 \pm 1.3$ & $46.8 \pm 0.5$ & $45.2 \pm 0.2$ & $392.8 \pm 1.8$ & $280.3 \pm 1.4$ & $20.1 \pm 0.2$ & $13.0 \pm 0.2$ \\
\hline & 60 & $158.1 \pm 0.4$ & $116.1 \pm 0.4$ & $46.4 \pm 0.2$ & $44.8 \pm 0.1$ & $463.5 \pm 6.3$ & $329.9 \pm 4.2$ & $22.7 \pm 0.4$ & $14.0 \pm 0.1$ \\
\hline \multirow{5}{*}{$\begin{array}{l}\text { Medfly } \\
\text { larvae }\end{array}$} & 20 & $98.4 \pm 0.3$ & $83.1 \pm 0.5$ & $49.1 \pm 0.2$ & $48.4 \pm 1.2$ & $341.8 \pm 2.6$ & $237.4 \pm 1.5$ & $19.2 \pm 0.3$ & $14.4 \pm 0.5$ \\
\hline & 30 & $106.7 \pm 0.5$ & $88.4 \pm 0.1$ & $49.3 \pm 0.3$ & $48.1 \pm 1.1$ & $414.2 \pm 3.5$ & $287.2 \pm 2.0$ & $20.4 \pm 1.1$ & $14.4 \pm 0.1$ \\
\hline & 40 & $115.2 \pm 0.6$ & $93.6 \pm 0.1$ & $49.5 \pm 0.9$ & $47.7 \pm 1.2$ & $495.8 \pm 7.4$ & $343.3 \pm 4.4$ & $22.7 \pm 1.1$ & $15.6 \pm 0.5$ \\
\hline & 50 & $124.7 \pm 0.5$ & $99.5 \pm 0.1$ & $48.9 \pm 0.9$ & $47.2 \pm 1.3$ & $589.0 \pm 15.9$ & $407.3 \pm 10.1$ & $26.0 \pm 1.7$ & $17.0 \pm 0.8$ \\
\hline & 60 & $134.5 \pm 0.6$ & $105.8 \pm 0.2$ & $48.8 \pm 1.4$ & $46.7 \pm 1.4$ & $703.3 \pm 31.6$ & $485.4 \pm 20.2$ & $29.3 \pm 1.6$ & $18.7 \pm 1.0$ \\
\hline \multirow{5}{*}{$\begin{array}{l}\text { Melon } \\
\text { fly }\end{array}$} & 20 & $104.7 \pm 1.7$ & $89.9 \pm 0.8$ & $59.0 \pm 0.4$ & $55.8 \pm 0.4$ & $379.7 \pm 5.7$ & $261.5 \pm 3.8$ & $19.8 \pm 0.3$ & $16.1 \pm 0.1$ \\
\hline & 30 & $109.2 \pm 2.0$ & $92.3 \pm 1.0$ & $58.4 \pm 0.5$ & $55.3 \pm 0.4$ & $438.8 \pm 4.6$ & $301.8 \pm 3.1$ & $21.2 \pm 0.2$ & $16.3 \pm 0.2$ \\
\hline & 40 & $115.1 \pm 2.7$ & $95.4 \pm 1.4$ & $57.7 \pm 0.5$ & $54.8 \pm 0.5$ & $520.1 \pm 6.1$ & $357.3 \pm 4.3$ & $23.4 \pm 0.3$ & $16.9 \pm 0.2$ \\
\hline & 50 & $123.4 \pm 2.7$ & $99.7 \pm 1.3$ & $57.3 \pm 0.5$ & $54.4 \pm 0.4$ & $624.7 \pm 3.0$ & $428.2 \pm 2.3$ & $26.6 \pm 0.2$ & $18.3 \pm 0.1$ \\
\hline & 60 & $141.1 \pm 1.2$ & $108.7 \pm 0.8$ & $57.4 \pm 0.4$ & $54.4 \pm 0.5$ & $772.3 \pm 6.9$ & $529.3 \pm 4.4$ & $31.3 \pm 0.2$ & $20.7 \pm 0.1$ \\
\hline \multirow{5}{*}{$\begin{array}{l}\text { Mexican } \\
\text { fruit fly }\end{array}$} & 20 & $90.3 \pm 13.6$ & $71.2 \pm 0.3$ & $48.5 \pm 3.4$ & $47.0 \pm 0.7$ & $343.9 \pm 15.1$ & $230.9 \pm 5.9$ & $17.5 \pm 2.0$ & $13.3 \pm 1.7$ \\
\hline & 30 & $105.1 \pm 21.5$ & $87.2 \pm 12.1$ & $47.3 \pm 3.5$ & $45.5 \pm 0.4$ & $384.7 \pm 15.2$ & $272.2 \pm 18.2$ & $21.3 \pm 3.9$ & $13.9 \pm 1.9$ \\
\hline & 40 & $117.4 \pm 28.2$ & $95.4 \pm 16.6$ & $46.4 \pm 2.9$ & $44.7 \pm 0.8$ & $446.1 \pm 19.0$ & $316.5 \pm 22.4$ & $24.2 \pm 5.1$ & $14.5 \pm 2.2$ \\
\hline & 50 & $128.7 \pm 33.6$ & $102.9 \pm 20.0$ & $45.7 \pm 2.3$ & $44.1 \pm 1.4$ & $521.8 \pm 32.1$ & $370.7 \pm 33.0$ & $26.8 \pm 5.7$ & $15.4 \pm 2.5$ \\
\hline & 60 & $141.2 \pm 37.5$ & $111.5 \pm 22.8$ & $44.5 \pm 2.0$ & $43.0 \pm 1.6$ & $582.2 \pm 28.1$ & $414.5 \pm 31.7$ & $29.4 \pm 5.9$ & $16.5 \pm 2.7$ \\
\hline \multirow{5}{*}{$\begin{array}{l}\text { Oriental } \\
\text { fruit fly }\end{array}$} & 20 & $99.3 \pm 11.3$ & $83.3 \pm 9.4$ & $52.8 \pm 5.9$ & $49.9 \pm 5.6$ & $399.1 \pm 8.6$ & $274.5 \pm 6.6$ & $19.3 \pm 1.1$ & $14.9 \pm 1.3$ \\
\hline & 30 & $104.1 \pm 13.1$ & $85.7 \pm 10.7$ & $51.8 \pm 6.4$ & $49.1 \pm 6.0$ & $460.8 \pm 6.6$ & $316.6 \pm 5.4$ & $20.9 \pm 1.2$ & $15.3 \pm 1.3$ \\
\hline & 40 & $110.6 \pm 16.2$ & $88.9 \pm 12.8$ & $50.8 \pm 6.8$ & $48.1 \pm 6.4$ & $541.6 \pm 11.7$ & $371.9 \pm 9.3$ & $23.2 \pm 1.5$ & $16.1 \pm 1.4$ \\
\hline & 50 & $121.4 \pm 18.4$ & $94.9 \pm 14.3$ & $50.9 \pm 6.3$ & $48.2 \pm 5.8$ & $664.4 \pm 4.0$ & $455.6 \pm 1.0$ & $27.1 \pm 1.0$ & $18.0 \pm 1.0$ \\
\hline & 60 & $137.7 \pm 22.7$ & $104.3 \pm 16.3$ & $51.9 \pm 5.9$ & $49.2 \pm 5.2$ & $820.6 \pm 10.6$ & $563.7 \pm 7.7$ & $32.6 \pm 1.6$ & $21.1 \pm 1.1$ \\
\hline
\end{tabular}




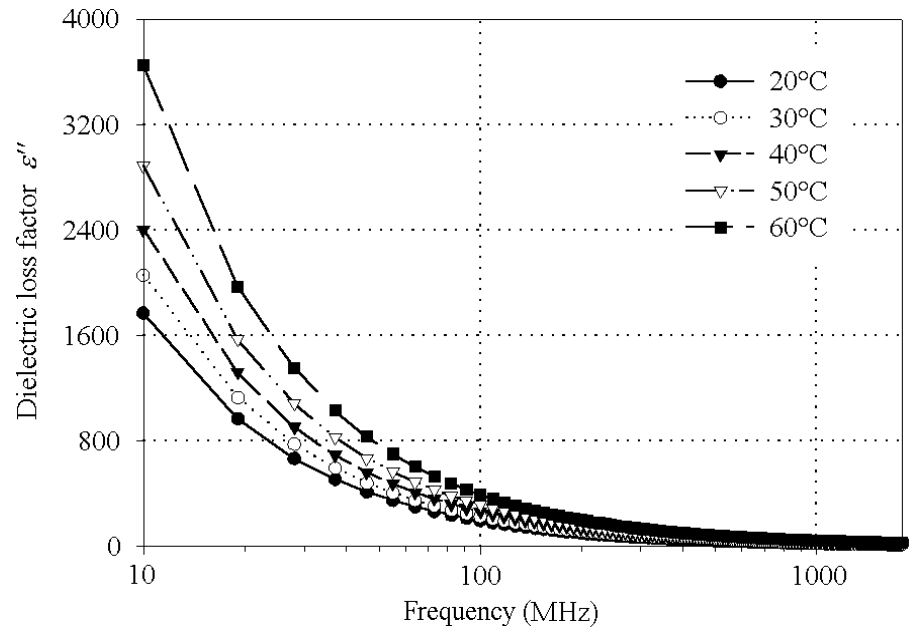

Figure 4. Dielectric loss factor of avocado as a function of temperatures and frequency.

Table 3. Penetration depths (cm) of the six tropical fruits calculated from the measured dielectric properties at $20^{\circ} \mathrm{C}$.

\begin{tabular}{lccc}
\hline Fruit & $27.12 \mathrm{MHz}$ & $915 \mathrm{MHz}$ & $1800 \mathrm{MHz}$ \\
\hline Avocado & 5.1 & 1.5 & 1.1 \\
Cherimoya & 9.4 & 1.5 & 1.1 \\
Longan & 9.7 & 3.3 & 1.5 \\
Passion fruit & 9.0 & 2.7 & 1.5 \\
Persimmon & 10.5 & 2.1 & 1.5 \\
White sapote & 9.0 & 1.8 & 1.3 \\
\hline
\end{tabular}

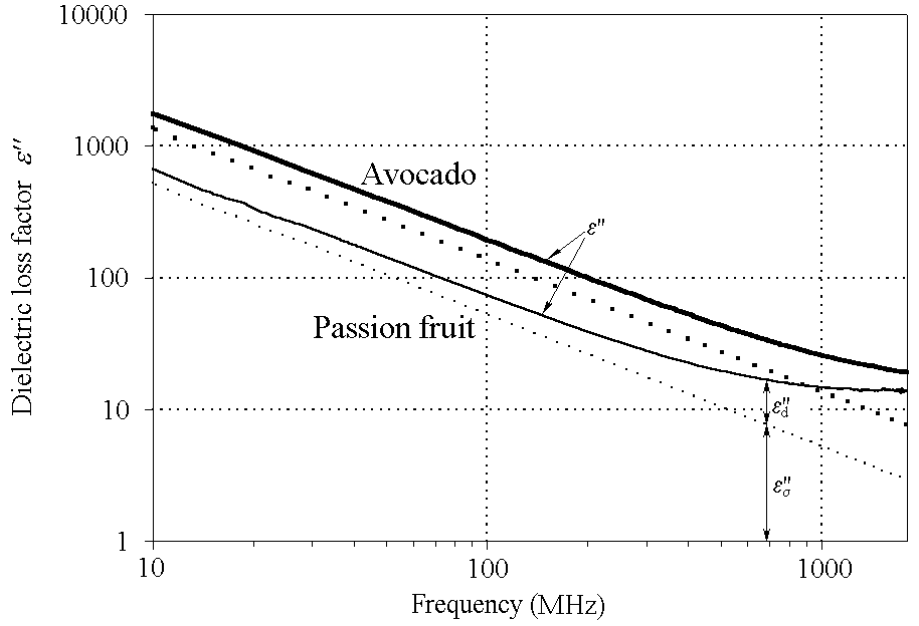

Figure 5. Measured $\varepsilon^{\prime \prime}$ (solid) and calculated $\varepsilon_{\sigma}^{\prime \prime}$ (dotted) of avocado and passion fruit as a function of frequency at $20^{\circ} \mathrm{C}$. The difference between $\varepsilon^{\prime \prime}$ and $\varepsilon_{\sigma}$ " represents the contribution from the dipole rotation of polar molecules $\left(\varepsilon_{d}{ }^{\prime \prime}\right)$.

targeted subtropical and tropical fruits, this method was applied to Red Delicious apples, Bing cherries, and navel oranges based on data reported in the literature (Ikediala et al., 2002; Wang et al., 2003b). A comparison of the electrical conductivity of the three fresh fruits obtained by estimating from the dielectric loss factor at $27.12 \mathrm{MHz}$ using equation 10 and by direct measurement with an electrical conductivity meter at $20^{\circ} \mathrm{C}$ is shown in table 5 . The $\mathrm{NaCl}$ concentration for a matched solution is also shown. The estimated electrical conductivity from $\varepsilon^{\prime \prime}$ was also higher than the measured value, and the difference ranged from $5 \%$ to $11 \%$ for these fresh fruits as with the subtropical and tropical fruit.
The suggested saline concentration is applicable in RF systems when the fruit is stationary and the effects of a thin fruit peel (e.g., apples) are negligible. However, the suggested saline concentration is not applicable if fruit movement is introduced in RF systems and a thick fruit peel (e.g., oranges) substantially affects the temperature pattern. In this case, the suggested concentration can be used as a maximum value in preliminary tests and gradually reduced to obtain a similar temperature in both the saline water and the fruit center. An immersion technique using a saline solution to match the dielectric loss factor of fresh fruits can be used to ensure uniform heating of the whole fruit in a 
Table 4. Comparison of electrical conductivity (mean $\pm \mathrm{SD}, \mathrm{mS} \mathrm{cm}^{-1}$ ) estimated from

the dielectric loss factor at 27.12 $\mathrm{MHz}$ and obtained from direct measurement with the electrical conductivity meter at $20^{\circ} \mathrm{C}$, and the matching saline solution for six subtropical and tropical fruits.

\begin{tabular}{lccc}
\hline & \multicolumn{2}{c}{ Electrical Conductivity $\left(\mathrm{mS} \mathrm{cm}^{-1}\right)$} & Suggested \\
\cline { 2 - 3 } & $\begin{array}{c}\text { Estimation from } \\
\text { the Dielectric } \\
\text { Loss Factor }\end{array}$ & Measurement & $\begin{array}{c}\text { Matching } \\
\text { NaCl Solution } \\
(\%)\end{array}$ \\
\hline Avocado & $10.56 \pm 0.16$ & $7.63 \pm 0.11$ & 0.42 \\
Cherimoya & $3.60 \pm 0.45$ & $3.42 \pm 0.08$ & 0.16 \\
Longan & $3.47 \pm 0.13$ & $3.17 \pm 0.09$ & 0.15 \\
Passion fruit & $3.83 \pm 0.13$ & $2.93 \pm 0.13$ & 0.13 \\
Persimmon & $3.13 \pm 0.22$ & $2.24 \pm 0.11$ & 0.08 \\
White sapote & $3.90 \pm 0.19$ & $3.21 \pm 0.36$ & 0.15 \\
\hline
\end{tabular}

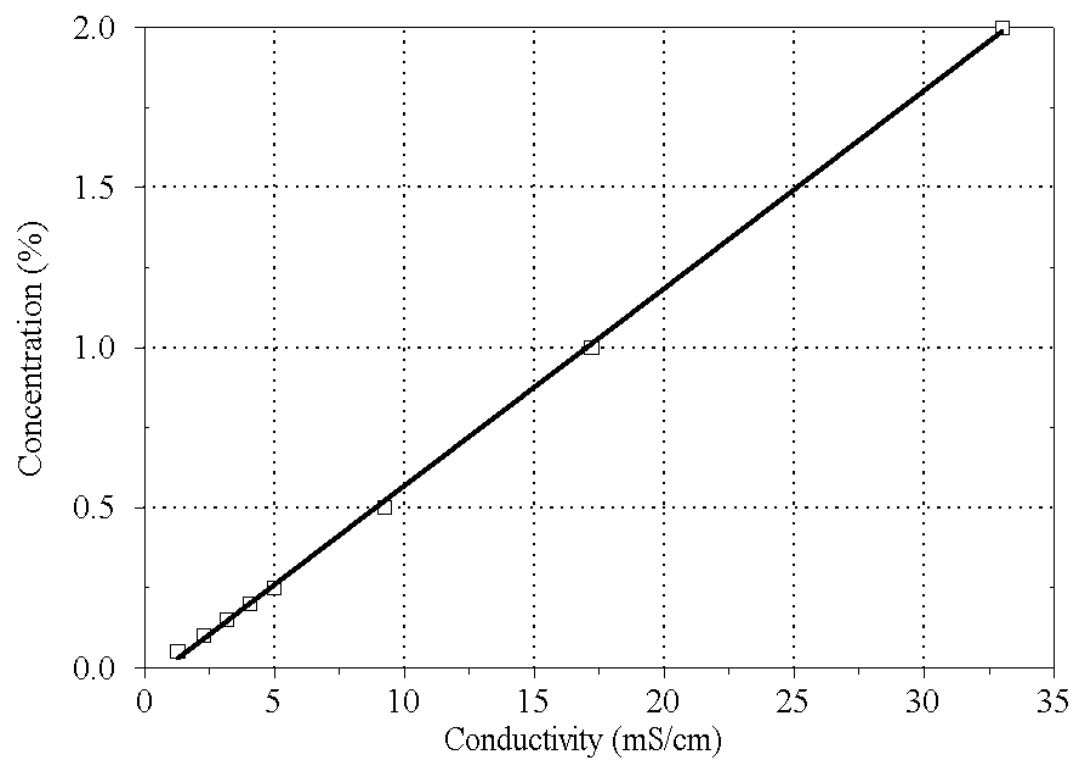

Figure 6. Relationship $\left(C=0.0617 \mathrm{\sigma}=0.0487, \mathrm{R}^{2}=0.999\right)$ between measured concentration $(C, \%)$ and conductivity $(\sigma, \mathrm{mS} \mathrm{cm}-1)$ of NaCl solutions at $20^{\circ} \mathrm{C}$ based on a previous study (Ikediala et al., 2002).

Table 5. Comparison of electrical conductivity (mean $\pm \mathrm{SD}, \mathrm{mS} \mathrm{cm}^{-1}$ ) estimated from the dielectric loss factor at $27.12 \mathrm{MHz}$ and obtained from direct measurement with an electrical conductivity meter at $20^{\circ} \mathrm{C}$, and the matching saline solutions for three fresh fruits reported in the literature.

\begin{tabular}{cccc}
\hline & \multicolumn{2}{c}{ Electrical Conductivity $\left(\mathrm{mS} \mathrm{cm}^{-1}\right)$} & \multicolumn{2}{c}{$\begin{array}{c}\text { Suggested Matching } \\
\text { NaCl Solution }(\%)\end{array}$} \\
\cline { 2 - 3 } Fruit & $\begin{array}{c}\text { Estimation from the } \\
\text { Dielectric Loss Factor }\end{array}$ & Measurement & 0.07 \\
Red Delicious apple & $2.10 \pm 0.01$ & $1.85 \pm 0.05$ & 0.21 \\
Bing cherry & $4.42 \pm 0.06$ & $4.20 \pm 0.12$ & Ikediala et al. (2002) \\
Navel orange & $3.37 \pm 0.01$ & $3.19 \pm 0.22$ & Ikediala et al. (2002) \\
Wang et al. (2003b) & & 0.15 \\
\hline
\end{tabular}

27.12 MHz RF system. Selection of the saline solution can be based on the simple measurement of electrical conductivity.

\section{Conclusions}

Dielectric properties of subtropical and tropical fruits and insects affected by frequency and temperature were determined with a suitable temperature control system and the open-ended coaxial-line probe technique. The dielectric loss factor of the fruits and the insects decreased with increasing frequency. Over the frequency range from 10 to about $300 \mathrm{MHz}$, the log of the dielectric loss factor deceased linearly with the log of the frequency. The close estimation of the dielectric loss factor from the electrical conductivity suggested that ionic conduction dominated the dielectric behavior in the RF range. The loss factor of avocado at low frequencies was the largest in comparison with those of other fruits and insects due to its high value of electrical conductivity. The loss factor of fruits and insects increased almost linearly with increasing temperature between $20^{\circ} \mathrm{C}$ and $60^{\circ} \mathrm{C}$. The same magnitude of the loss factor of the subtropical and tropical fruits and the insects suggested that no differential heating of insects in these fruits will occur when they are treated at together in an RF system. A successful treatment process can still be possibly developed 
using RF energy if the insects are killed thermally before the fruit quality is damaged. The new information of the electrical conductivity of the fruits can be used to estimate the required saline solution for matching the dielectric loss factor to obtain relatively uniform heating of the whole fruit when an immersion technique is applied in an RF system.

\section{ACKNOWLEDGEMENTS}

This research was supported by grants from USDACSREES (2004-51102-02204), BARD (The United StatesIsrael Binational Agricultural Research Development Fund, US-3276-01), and the California Department of Food and Agriculture (02-0652). We thank Steve Brown (USDA-ARS, Hilo, Hawaii) for technical assistance in insect preparation.

\section{REFERENCES}

Andreuccetti, D., M. Bini, A. Ignesti, A. Gambetta, and R. Olmi. 1994. Microwave destruction of woodworms. J. Microwave Power and Electromagnetic Energy 29(3): 153-160.

Armstrong, J. W. 1994. Heat and cold treatments. In Insect Pests and Fresh Horticultural Products: Treatments and Responses, 103-119. R. E. Paull and J. W. Armstrong, eds. Wallingford, U.K.: CAB International.

Birla, S. L., S. Wang, J. Tang, and G. Hallman. 2004. Improving heating uniformity of fresh fruits in radio frequency treatments for pest control. Postharvest Biol. Tech. 33(2): 205-217.

Colpitts, B., Y. Pelletier, and S. Cogswell. 1992. Complex permittivity measurements of the Colorado potato beetle using coaxial probe techniques. J. Microwave Power and Electromagnetic Energy 27(3): 175-182.

Feng, H., J. Tang, and R. P. Cavalieri. 2002. Dielectric properties of dehydrated apples as affected by moisture and temperature. Trans. ASAE 45(1): 129-135.

Foster, K. R., and H. P. Schwan. 1989. Dielectric properties of tissues and biological materials: A critical review. Crit. Rev. Biomed. Eng. 17(1): 25-104.

Guan, D., M. Cheng, Y. Wang, and J. Tang. 2004. Dielectric properties of mashed potatoes relevant to microwave and radio-frequency pasteurization and sterilization processes. $J$. Food Sci. 69(1): 30-37.

Holland, B., I. D. Unwin, and D. H. Buss. 1992. Fruits and Nuts: First Supplement to the Fifth Edition of McCance and Widdowson's the Composition of Foods. London, U.K.: Royal Society of Chemistry and Ministry of Agriculture, Fisheries and Food.

Hallman, G. J., and J. L. Sharp. 1994. Radio frequency heat treatments. In Quarantine Treatments for Pests of Food Plants, 165-170. J. L. Sharp and G. J. Hallman, eds. San Francisco, Cal.: Westview Press.

Ikediala, J. N., J. Tang, L. G. Neven, and S. R. Drake. 1999. Quarantine treatment of cherries using $915 \mathrm{MHz}$ microwaves: Temperature mapping, codling moth mortality, and fruit quality. Postharvest Biol. Tech. 16(2): 127-137.

Ikediala, J. N., J. Tang, S. R. Drake, and L. G. Neven. 2000. Dielectric properties of apple cultivars and codling moth larvae. Trans. ASAE 43(5): 1175-1184.
Ikediala, J. N., J. D. Hansen, J. Tang, S. R. Drake, and S. Wang. 2002. Development of saline water immersion technique with RF energy as a postharvest treatment against codling moth in cherries. Postharvest Biol. Tech. 24(1): 25-37.

Kent, M. 1987. Electrical and Dielectric Properties of Food Materials. A Cost90bis production. Essex, U.K.: Science and Technology Publishers.

Metaxas, A. C., and R. J. Meredith. 1993. Industrial Microwave Heating. IEE Power Engineering Series 4. London, U.K.: Peter Peregrinus.

Mitcham, E. J., R. H. Veltman, X. Feng, E. de Castro, J. A. Johnson, T. L. Simpson, W. V. Biasi, S. Wang, and J. Tang. 2004. Application of radio frequency treatments to control insects in in-shell walnuts. Postharvest Biol. Tech. 33(1): 93-101.

Nelson, S. O. 1996. Review and assessment of radio-frequency and microwave energy for stored-grain insect control. Trans. ASAE 39(4): 1475-1484.

Nelson, S. O., 2003. Frequency- and temperature-dependent permittivities of fresh fruits and vegetables from 0.01 to 1.8 GHz. Trans. ASAE 46(2): 567-574.

Nelson, S. O., and J. A. Payne. 1982. RF dielectric heating for pecan weevil control. Trans. ASAE 25(2): 456-458.

Ryynänen, S. 1995. The electromagnetic properties of food materials: A review of the basic principles. J. Food Eng. 26(4): 409-429.

Seo, S. T., D. L. Chambers, M. Komura, and C. Y. L. Lee. 1970. Mortality of mango weevils in mango treated by dielectric heating. J. Econ. Ent. 63(3): 1977-1978.

Sheen, N. I., and I. M. Woodhead. 1999. An open-ended coaxial probe for broad-band permittivity measurement of agricultural products. J. Agric. Eng. Res. 74(2): 193-202.

Tang, J., J. N. Ikediala, S. Wang, J. D. Hansen, and R. P. Cavalieri. 2000. High-temperature short-time thermal quarantine methods. Postharvest Biol. Tech. 21(1): 129-145.

Tang, J., H. Feng, and M. Lau. 2002. Microwave heating in food processing. In Advances in Agricultural Engineering, 1-44. X. Yang and J. Tang, eds. New York, N.Y.: Scientific Press.

Venkatesh, M. S., and G. S. V. Raghavan. 2004. An overview of microwave processing and dielectric properties of agri-food materials. Biosystems Eng. 88(1): 1-18.

Von Hippel, A. R. 1954. Dielectric Properties and Waves. New York, N.Y.: John Wiley.

Wang, S., J. N. Ikediala, J. Tang, J. D. Hansen, E. Mitcham, R. Mao, and B. Swanson. 2001. Radio frequency treatments to control codling moth in in-shell walnuts. Postharvest Biol. Tech. 22(1): 29-38.

Wang S., J. Tang, J. A. Johnson, E. Mitcham, J. D. Hansen, R. P. Cavalieri, J Bower, and B. Biasi. 2002. Process protocols based on radio frequency energy to control field and storage pests in in-shell walnuts. Postharvest Biol. Tech. 26(3): 265-273.

Wang, S., J. Tang, R. P. Cavalieri, and D. Davis. 2003a. Differential heating of insects in dried nuts and fruits associated with radio frequency and microwave treatments. Trans. ASAE 46(4): 1175-1182.

Wang, S., J. Tang, J. A. Johnson, E. Mitcham, J. D. Hansen, G. Hallman, S. R. Drake, and Y. Wang. 2003b. Dielectric properties of fruits and insect pests as related to radio frequency and microwave treatments. Biosystems Eng. 85(2): 201-212.

Wang, Y. F., T. D. Wig, J. M. Tang, and L. M. Hallberg. 2003c. Dielectric properties of foods relevant to RF and microwave pasteurization and sterilization. J. Food Eng. 57(3): 257-268. 
